\title{
Characterization of Single Enset Fiber Tensile Properties Using Optimal Experimental Design and Digital Image Correlation Technique
}

\author{
Abebayehu Abdela ${ }^{1, \text { *, }}$ Mark Versteyhe ${ }^{2}$, Fasil Taddese ${ }^{1}$ \\ ${ }^{1}$ Ethiopia Institute of Technology-mekelle, Mekelle University, Mekelle, Ethiopia \\ ${ }^{2} \mathrm{KU}$ Leuven, Mechanical Engineering Technology Campus Bruges, Bruges, Belgium
}

Email address:

abexmese@yahoo.com (A. Abdela), mark.versteyhe@kuleuven.be (M. Versteyhe), fasiltadesse@gmail.com (F. Taddese)

${ }^{*}$ Corresponding author

\section{To cite this article:}

Abebayehu Abdela, Mark Versteyhe, Fasil Taddese. Characterization of Single Enset Fiber Tensile Properties Using Optimal Experimental Design and Digital Image Correlation Technique. International Journal of Mechanical Engineering and Applications.

Vol. 8, No. 1, 2020, pp. 8-15. doi: 10.11648/j.ijmea.20200801.12

Received: March 13, 2019; Accepted: December 31, 2019; Published: January 9, 2020

\begin{abstract}
With the majority of the world's fiber use relying on wood, cotton and petrochemicals, the use of alternative fiber sources in manufacturing is rapidly gaining importance in reaching the Sustainable Development Goal's on innovation and responsible production. Lucidly, Enset is a main staple crop in southern and central Ethiopia where the pulp is fermented for food production but its strong fibers are now only used for local rope making or they are discarded. Hence, importance of processing this agricultural product for industrial application is explicit and characterization is, thus, mandatory. This paper presents the characteristics of a single Enset fiber in tension using Optimal Experiment Design and Digital Image Correlation techniques. To do so, Enset fiber sample with $10 \mathrm{~cm}$ length glued to sand paper case with TIPIX application and speckle formation is prepared. Fiber density is measured by a Pycnometer to estimate a cross sectional area. Then, a known amount of load has been gradually applied until failure. And, images are taken while the extension is taking place using the limes camera. The retort of every point is used with analogue data to make a correlation using correlated solution software (Vic2D), and related scrutiny to determine fiber properties. Bundle test has also been used to reinforce the result. This work reports the properties of the fiber to be: Density: $1.4 \mathrm{~g} / \mathrm{cm} 3$; Strength: 67Mpa-923Mpa, Mean strength: 647MP; E modulus: 12Gpa-69Gpa, Mean E modulus: 46MPa. Here, the major reason behind the smallest value in the range is the manual fiber extraction utilized in light of extracting the pulp.
\end{abstract}

Keywords: Fiber, Enset, Processing, Pycnometer

\section{Introduction}

Fiber-reinforced composite materials want to be used in a large number of applications ranging from aerospace systems to automotive, industrial, and consumer products [15]. These fibers can be either synthetic or natural. In recent years, the amount of research on natural fibers products has increased considerably [7]. Besides, ample recent findings favor natural fiber over synthetic ones for many reasons. For instance, natural fiber can be a relevant substitute of synthetic fibers since they are available naturally in a fiber form at low costs and they reach relatively high specific strength and rigidity owing to their low density [3]. Replacing of the synthetic fibers by the natural ones, thus, has a lot of benefits which can be rationalized also by means of an ecological equilibrium since natural fibers are eco-friendly while encompassing good properties compared to synthetic fibers. Other reason for this increase is due to a greater consciousness of the ever depleting trend of petroleum supplies [7]. Thus, Natural fibers have a big role to play towards a sustainable environmentally friendly future [7]. Besides, composite materials reinforced with natural fibers become more significant in constructional applications. For instance, natural fibers from coir, kenaf, oil palm jute have suitable mechanical properties which are used in various industrial applications [13, 10, 12]. They also have some drawbacks owing to their low plasticity. Generally, current global ecological and economic interests arouse research in 
designing new materials whose considerable portion is based on natural resources in order to avoid further pressure on the environment [2]. As a result, constantly increasing trend of using natural fiber as reinforcement in composite materials based on epoxy resin has been seen in recent years.

One of the suitable plants with great potential for the production of natural fibers with competitive properties is Ensete (Ensete ventricosum) Ethiopian plant. The Ministry of Agriculture and Natural Resources of Ethiopia reported that Enset is one of the important indigenous food crops where an estimated 15-20 million people mostly in the SNNP, parts of Oromia and Gambela States support livelihoods as staple food. The pulp is fermented for food production but its strong fibers are now only used for local rope making or they are discarded. Jointly, selling the fibers for manufacturing uses would be a win-win situation for both the industries and the farmers, and provide the latter with a much needed source of additional income because composite material reinforced with Ensete fibers can be used for diverse industrial application including the production of parts for automotive industry. In this regard, the main challenges during the scheme of this feat would be the existing enormous varieties of the plant in the country depending on different reasons including, agro ecological zones, soil type, environment etc. And, processing this agricultural products and making them input for industries would be important contribution to the development of agriculture, agro processing and industries. Thus, characterization of the fiber is required.

Researchers [1, 5, 11] already tried to establish characteristics of the fiber at composite level. Single fiber test using the technique of digital image correlation is relatively accurate in depicting the tensile properties with lesser standard deviation amid the results. However, the direct single fiber tensile characteristic using the direct method hasn't been dealt with for this fiber yet, as a way to determine the fiber's mechanical properties at material development stage. As well, this method, single fiber test, is considered as a preferred method when a limited quantity of material is available [6]. This resulting fiber's tensile properties are needed to perform different micromechanical analyses and mechanical modeling of these materials as well as their composites. Bundle test result reinforcement has also been utilized to characterize the fiber. Besides, the test to be performed has to incorporate the appropriate the gauge length, the strain rate (viscoelastic behavior of the fibers), the environmental conditions (hygroscopic behavior of natural fibers) and the gripping method (gripping of frame or fiber) $[9,16]$.

The cross sectional area of the fiber which is assumed to be circular varies across the length of a single fiber as well as between different fibers of the same plant [15]. This is one of the challenges in finding the minimum amount of the fibers sample or specimen required to come up with representative results. This work uses JMP software package from SAS to determine the optimal number of measurements. Using the technique progressively at single and bundle samples level helps to identify the minimum number of experiments [5].
Moreover, a bundle specimen made using compression molding; is used to measure the properties of the fiber via back calculation to compare the result for validation. The properties are identified for the aligned fiber orientation because the best mechanical properties can generally be obtained for composites when the fibre is aligned parallel to the direction of the applied load [20, 21 and 22]. One study on aligned Alfa fibre reinforced showed strengths compared to those obtained in the fibre direction (00) of $69 \%, 29 \%$, $22 \%$ and $12 \%$ at angles of $100,300,450$ and 900 respectively and corresponding Young's moduli of 93\%, $66 \%, 52 \%$ and $41 \%$ of that in the fibre direction [23]. In another study on hemp/PLA composites, those with fibre aligned at 450 and 900 were found to have $48 \%$ and $30 \%$ of the strength and $53 \%$ and $42 \%$ of the Young's moduli of those with 00 fibre [24]. In this work, Enset fiber characteristics have been studied using digital image correlation and optimal number of runs (experiment).

\section{Materials and Methods}

\subsection{Enset Fibers}

The Enset fibers displayed on figure 1C below were sourced from Enset plant (Ensete ventricosum) shown on figure 1A below from, Kokosa wereda, West Asri zone Oromia, Ethiopia at 2628 meters above sea level with an annual average temperature of $21 \mathrm{LC}$ and an annual average precipitation of $2300 \mathrm{~mm}$ and a relative humidity of $81 \%$ according to the environmental authorities of the region.
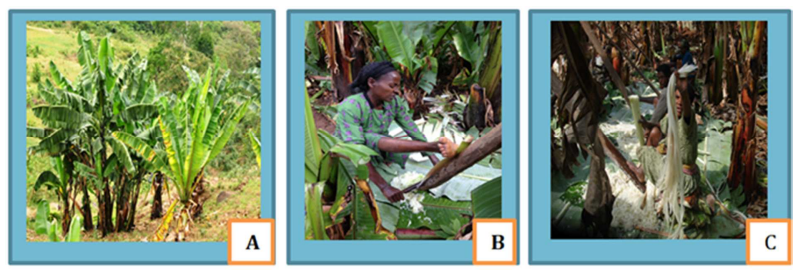

Figure 1. A) Enset plant B) Manual extraction C) Enset fiber.

For this research, manually (figure 1B) extracted Enset fibers using an in house developed technique meant only for extracting the pulp (Edible part Enset) is used. Three Enset plant with different ages, after maturity time which varies from plant to plant, $(1.5,2$, and 2.5 years $)$ with no previous characterization for their mechanical properties are considered. The density of the fibers was determined using a gas Pycnometer, Beckman model 930, in which helium gas at a pressure of 0.5 bar was used as the displacement medium. During material preparation prior to the density measurement, the fibers were cut to a length of $1 \mathrm{~cm}$ and vacuum dried for $24 \mathrm{hr}$ at $60 \mathrm{LC}$ [5]. The mass of these fibers to determine the density is then measured using sensitive balance with accuracy to $10-5 \mathrm{~g}$. The measured density was $1.4 \pm 0.03$ $\mathrm{g} / \mathrm{cm} 3$. For the single fiber tensile tests, the fibers were cut to a length of $10 \mathrm{~cm}$, dried for $24 \mathrm{hr}$ at $60 \mathrm{LC}$ and subsequently conditioned at $50 \%$ relative humidity $(\mathrm{RH})$ and $21 \mathrm{LC}$ for 24 $\mathrm{hr}$. In the latter condition, the mass of the fibers was measured 
using an analytical balance (Mettler AT 261 Delta Range, Mettler Toledo) accurate to $10-5 \mathrm{~g}$ to calculate the average cross sectional area using equation 1 below, which is important for calculation of strength of the fiber from the known loads from machine reading.

$$
\mathrm{A}=\frac{m}{l \grave{\rho}}
$$

In the above equation $\mathrm{m}$ is the fiber mass $\dot{\rho}$ is the fiber density and 1 is the fiber length.

The fiber used for bundle test are also dried for $48 \mathrm{hr}$ at 60 $\mathrm{LC}$ and later conditioned at 50\% RH and $21 \mathrm{LC}$. Three volume fractions $(35 \%, 40 \%$ and $45 \%)$ have been considered while designing the experiment. The following equation is used to determine the mass of fiber, volume of fiber, resin and hardener mass required.

$$
\mathrm{FVF}=\frac{1}{1+\frac{\dot{\rho} f}{\dot{\rho} m}\left(\frac{1}{f v f}-1\right)}
$$

In the above equation FVF is fiber volume fraction, $\rho$ f is the fiber density and $\dot{\rho} m$ is the matrix density.

\subsection{Sampling and Experimental Design}

To get representative results of the individual and collective tests, the experiments have been designed and the factors affecting the result are also included in the design. While including the factors, main effects (the effect they have individually) of the factors and the 2-level interaction effects (the combined effect of any two of the factor) of the parameter have also be considered, the summary of the upshot is presented in result and discussion part shown under part 3 below. In line with this, single Natural fibers always have different cross-sectional area and non-uniform cross sectional area across the length of a fiber. Thus, there has to be a minimum amount of runs (experiments) required based on the factors affecting the standard deviation between the results. This has to be done at both single fiber test meant to study the characteristics in tension and the bundle test meant to reinforce the result of the single fiber test. A software package from SAS Company (JMP pro 13) has been used to design optimal experiment model. The JMP software's DOE platforms helped to design experiments. There are two kinds of parameters or factors (categorical and continuous) considered. These parameters include, volume fraction, extensions rate, gauge length and loading condition. Inline, D-Optimality and I-Optimality criteria have been utilized.

\subsection{Single Fiber Tensile Test Set-up}

To perform the single fiber test in tension, an individual Enset fiber is cut to $10 \mathrm{~cm}$ length with known measured mass using an analytical balance (Mettler AT 261 Delta Range, Mettler Toledo) accurate to $10-5 \mathrm{~g}$ and calculated diameter was glued onto abrasive paper (PS11A grain 1000, Klingspor) frame using a double-sided glue roller (Permanent Pritt glue roller, Henkel). The mass of the individual fibers differ because of irregularity and non-uniformity across the length.
Plus, the diameter varies for every individual fiber because of mass difference emanated from irregularity and non-uniformity again. Hence, the mass of the $10 \mathrm{~cm}$ length is measured for individual fibers and used to find the diameter of each fiber. Consequently, the diameter of individual fiber is calculated for every fiber using the equation 4 . The figure below shows the frame dimensions for a test gauge length and the position of the fiber in this frame. Speckles made by spraying of paint on the samples prepared are also engendered to support the correlation process using Vic2D. The frame helps sample mounting and fiber alignment in the grips, whereas the abrasive paper minimizes fiber slippage during the test.

$$
\mathrm{D}=\sqrt{\frac{4 m}{l \dot{\rho} \pi}}
$$

On equation 4above, $\mathrm{D}$ is diameter of the fiber, $\mathrm{m}$ is mass of the fiber, $\rho$ is density and 1 is length of the fiber.

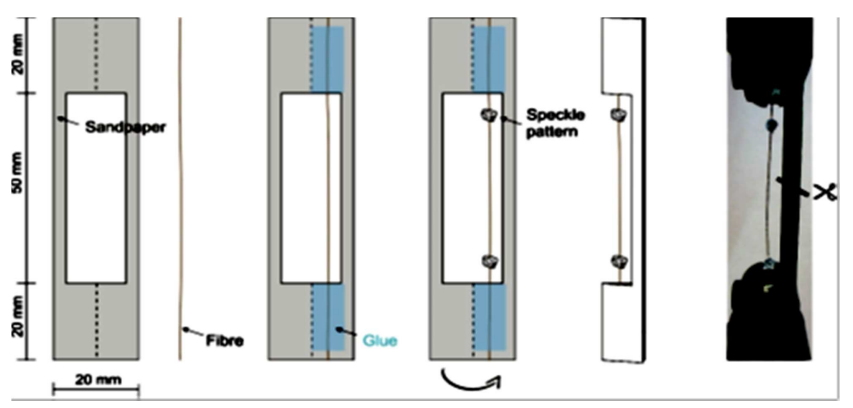

Figure 2. Sand paper frames and fiber preparation.

Single fiber tensile tests were performed on an Instron 5943 equipped with a $100 \mathrm{~N}$ load cell according to the ASTM C1557-14 standard in a conditioned environment at 50\% RH and 21 LC. Properties determined by this test method are valuable in the assessment of new fibers at the research and development stages. The frame was pneumatically gripped with a gripping force of $200 \mathrm{~N}$. An average preload of $0.015 \mathrm{~N}$ was applied to the fiber to straighten the fiber which is critical when the strain is to be derived from the crosshead displacement. This method is in agreement with result on literature [5]. Too, the upper grip is linked to the load cell with a ball joint which ensures the alignment of the fiber in the first stages of the test. The crosshead displacement rate was chosen according to the ASTM C1557-14 standard, which suggests achieving fracture within 30 s of testing. Yet, three different crosshead displacements with potential to achieve the value are used in the process of optimal design of experiment $1,1.25$, $1.5 \mathrm{~mm} / \mathrm{min}$. For the investigated fibers, this translates to a crosshead displacement rate of $1.25 \mathrm{~mm} / \mathrm{min}$.

Digital image correlation is powerful tool to measure the strain of a fiber fiber. For this test, the specimens were attached to an abrasive frame as outlined on the figure 3 above. Additionally, two optical flags with an approximate diameter of $4 \mathrm{~mm}$ were attached to the fiber surface using white correction fluid (correction pen Tipp-Ex, Bic World). On these white flags a black speckle pattern was applied with spray 
paint. According to [6] rotations or movements in the plane of the sand paper do not affect the strain measurement as in the case of indirect strain measurement. The out-of-plane motion (forward and backward fiber movement relative to the camera) does affect the strain measurement significantly and care should be taken to limit this movement during the test [5]. For the registration of the images during tensile testing, a digital camera (Limess messtechnik \& software GmbH, Krefeld, Germany) with a spatial resolution of 96 dpi, equipped with a Componon-S 2.8/50 lens (Schneider Kreuznach, Bad Kreuznach, Germany), were used. The distance between sample and camera was $1 \mathrm{~m}$ adopted from [5]. Samples were illuminated frontally with a $350 \mathrm{~W}$ halogen lamp. Subsequent images and force registration were taken during the test with an interval of $150 \mathrm{~ms}$ using acquisition software (LimShot, Limess messtechnik \& software GmbH, Krefeld, Germany).

\subsection{Bundle Test Setup}

\subsubsection{Mold Preparation}

The standard mold used to prepare specimens using the fiber volume fractions (FVF) which is considered categorical factor during experiment design, is a rectangular prism. The internal dimension of the rectangular prism equals $\left(2 \times 10 \times 20=400 \mathrm{~mm}^{3}\right)$. Hence the expected volume of the composite would be nearly the same, if the process of impregnation is taken care of properly. The volume fraction and related estimation is also taken from this prism volume and interpreted in terms of mass by using the relationship between density, mass and volume demonstrated on equation 3 above. $2 \mathrm{~mm}$ thick aluminum spacers are used at two ends of the mold to generate uniformly distributed $2 \mathrm{~mm}$ thickness of the specimen meant to perform bundle test up on completion of the specimen's preparation. The spacers are less than the opening on the mold to allow the removal of extra resin during hot pressing.

$$
\dot{\rho}=\frac{m}{v}
$$

On equation 4 above, $m$ is mass of the fiber, $\rho$ is density and $\mathrm{v}$ is volume of the fiber.

\subsubsection{Sample Preparation and Compression}

The minimum number of samples designed by the optimal design of experiment is prepared using the aforesaid mold (rectangular prism). Mass fraction derived from the volume fractions used using equation 2 above. Aceton and release agents are also used to clean the molds part and allow simple de-molding after compression molding using hot pressing respectively. The fiber is then impregnated in to the resin (Epoktet 828 LVEL, a from Hexion company) found using equation 2 and mixed with 15.2\% hardener (Dytek DCH-99). After mixing the hardener with the resin, vacuum degassing was used to remove the bubble and air gaps which may affect the result. Then, the impregnated fiber is located on the plastic cover and pressed in to the mold manual to make it ready for hot pressing machine. Compressing molding is used to prepare specimens to study the unidirectional fiber properties at composite level. The result was meant to be used as an input for different analysis vital to reinforce the single fiber tests mentioned above. The specimen made is pressed under hot press machine at a temperature of $70^{\circ} \mathrm{C}$ for 1 hour and then $150^{\circ} \mathrm{C}$ for additional 1 hour after being pressed. High temperature resistant foam has been used to allow uniform compression load distribution across every specimen included on a mold. Up on completion of the 2 hours standards time, the mold was removed and air cooled. After cooling, the de-molding has been done and the samples are then treated at $60^{\circ} \mathrm{C}$ for 24 hour to attain the required result. Then, the specimen is made ready for test as it is displayed on the figure below.

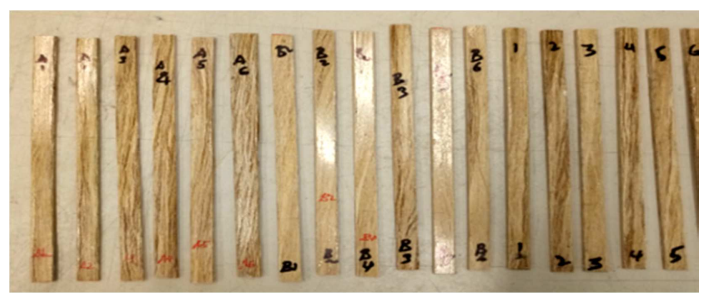

Figure 3. Specimen produced using compression molding and ready for tensile test.

\subsubsection{Composite Tensile Test Set Up}

To perform tensile test of composite specimens stated above an ASTM test standard with D3039/D3039M-08 designation is utilized. The universal tensile testing machine on which the test was conducted is Instron 5567. 1KN and $30 \mathrm{KN}$ load cell are used is with $12.5 \mathrm{~mm}$ extensometer supplement to show the effect of intermittent loading and maximum strength respectively. Then, series of test have been conducted on the samples using the Bluehill software working in integration with Instron 5567, the universal tensile testing machine. The rate of expansion used in this project is $1 \mathrm{~mm} / \mathrm{s}$ and the strength at failure, E modulus at failure and the strain at failure has been deployed from the machine and used for analysis meant to reinforce the single fiber test and related characteristic.

\section{Result and Discussion}

\subsection{Optimal Experiment}

The experiments have been designed using JMP 13 pro software package. The DOE platform is mainly used to get the optimal design result and the analysis platform to perform the study. The main effect and the interaction effect with 2-level has been considered in the process. Constraints are also inputted in to the software to make the experiment more real replica of the situation. Then, the minimum number of experiment recommended by JMP has been made with additional experiments, depending on the type and the importance, for boosting the certainty of the result as it is tabulated on table 1 here below. And, $r$ test has been made using the same software and has been taken in to account for both main effect and interaction effect of the parameter for their level of significance. 
Table 1. Summary of the optimal number of experiment.

\begin{tabular}{lllll}
\hline S. N & Test type & Categories & Min. test & Test done \\
\hline \multirow{3}{*}{1} & \multirow{3}{*}{ Single fiber } & Category 1 & 24 & 30 \\
& & Category 2 & 24 & 30 \\
& & Category 2 & 24 & 30 \\
\multirow{2}{*}{2} & \multirow{3}{*}{ Bundle test } & Category 1 & 15 & 20 \\
& & Category 2 & 15 & 20 \\
& & Category 2 & 15 & 20 \\
\hline
\end{tabular}

As it is depicted above, extra six tests are added for each single fiber test and additional 5 tests for bundle test. These additions help to enhance the reliability and representativeness of the result more.

\subsection{Single Fiber Test Result}

The result found from the Instron tensile testing machine analog data after the conclusion of the test has been used as an input to the simulated correlation system. And, the correlation made with Vic2D has taken care of the acceptable error range which is less that $5 \%(0.05)$ for every points and tests as on. Hence, the correlation is acceptable and only few instances of the result are highlighted on the table 2 below.

Table 2. Correlation error test.

\begin{tabular}{llll}
\hline File & Points & Time & Error (\%) \\
\hline 00001_0.tif & 408 & 0.125 & 2.72 \\
00002_0.tif & 403 & 0.119 & 2.70 \\
00003_0.tif & 403 & 0.121 & 2.73 \\
.... & & & \\
Average & 352.6066 & 0.145251 & 3.44 \\
\hline
\end{tabular}

After the error level has been found to be acceptable, less than $5 \%$, the resulting table incorporating the load and extension has been used with calculated area of the single fibers. Consequently, a result from correlated solution jointly with manual analyses done, the range of the strength lay between $67 \mathrm{Mpa}$ and $923 \mathrm{Mpa}$ while the average strength is $647 \mathrm{MPa}$ for the chosen variety of the fiber. Having the acceptable range of correlation error, the stress strain curve has been developed for three categories of the tests mentioned above and resulted in the characteristics displayed on figure 4 below.
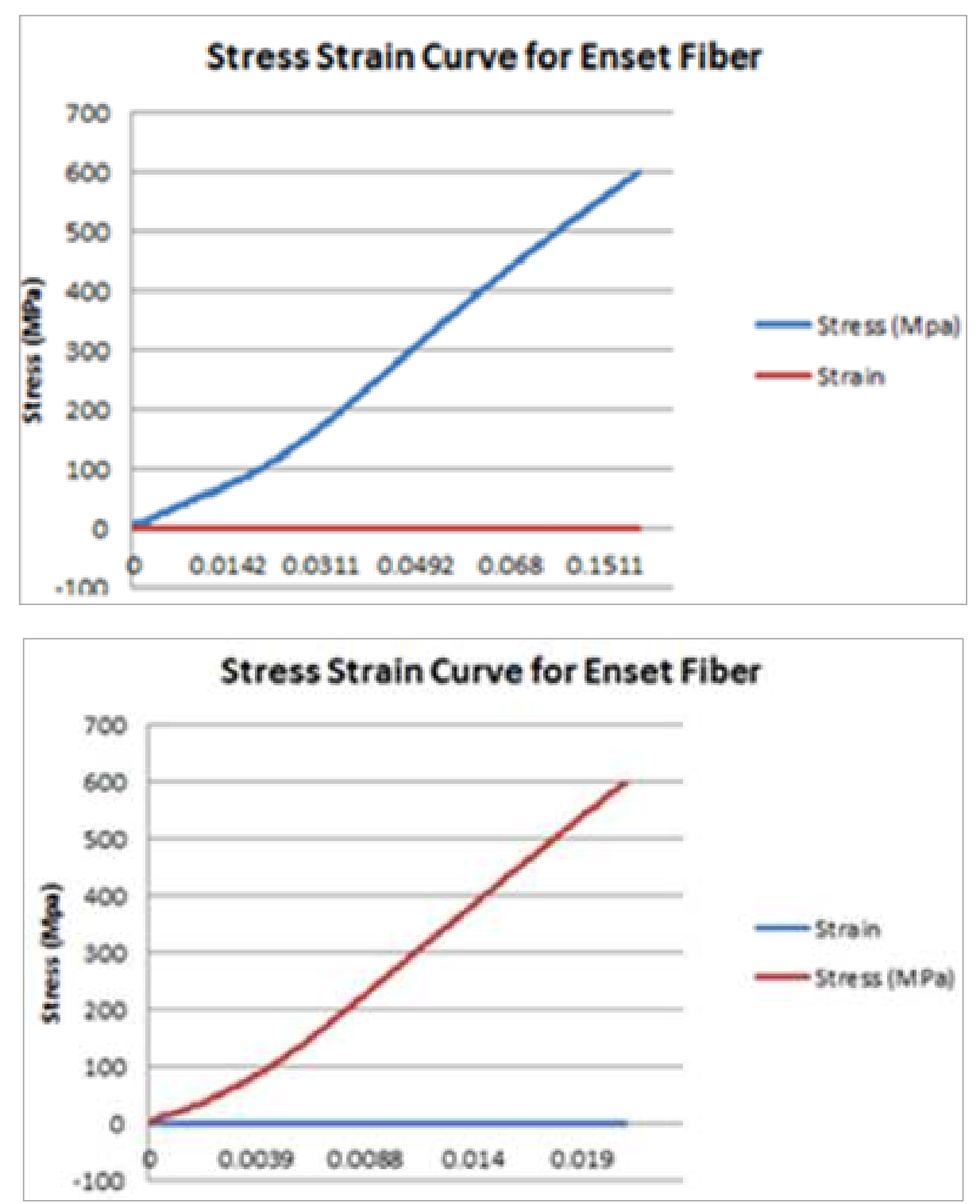


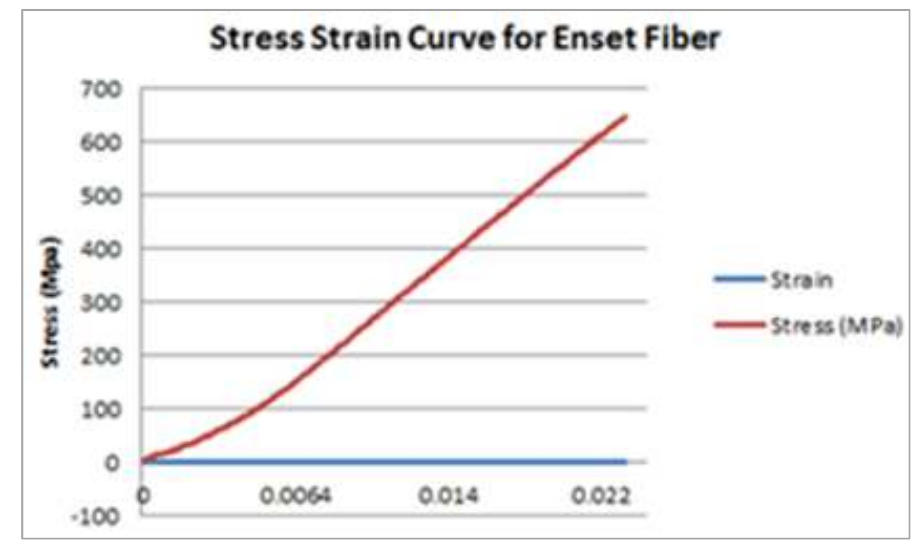

Figure 4. Stress strain curve for Enset fiber.

Therefore, the overall result of the fiber characteristics for all categories of the test under tension in terms of strength and $\mathrm{E}$ modus value can be summarized on table 3 below.

Table 3. Characteristics of the fiber.

\begin{tabular}{llllll}
\hline S. N & \multirow{2}{*}{ Category } & Parameter & $\begin{array}{l}\text { Lower } \\
\text { (MPa) }\end{array}$ & $\begin{array}{l}\text { Upper } \\
\text { (MPa) }\end{array}$ & $\begin{array}{l}\text { Mean } \\
\text { (GPa) }\end{array}$ \\
\hline \multirow{2}{*}{1} & \multirow{2}{*}{ Category 1 } & Strength & 41 & 723 & 542 \\
& & E Modulus & 3.5 & 65 & 49 \\
2 & \multirow{2}{*}{ Category 2 } & Strength & 51 & 821 & 618 \\
& & E Modulus & 46 & 68 & 51 \\
3 & \multirow{2}{*}{ Category 3 } & Strength & 67 & 923 & 647 \\
& E Modulus & 12 & 69 & 46 \\
\hline
\end{tabular}

As it is displayed here above, the lowest limits of the strength have been resulted from different reasons. The main reason behind can be the fiber manual extraction method which has a potential to damage the fiber. This damage on the fiber would allow it to break early during continues loading and it would characterize the fiber with low strength. The other category of the fiber with low strength failed at the clamp or near the clamp which mighty have resulted damage of the fiber that the Poisson ration is affected. The breakage at the clamp has been registered to be about $4.4 \%$ of the test. Thus, enhancing the extraction means to preserve the fiber during extraction will minimize breakage and increase the strength as a result.

As it is mentioned above mass of the each fiber was measures and it is from 0.0006 to $0.0021 \mathrm{gr}$. Since the density of the fiber has been found to be $1.4 \mathrm{gr} / \mathrm{cm} 3$, the cross sectional area of each fiber has been calculated equation 3 and equation 4 above. Even though mass and area are directly proportional, the following figure shows variation unpredictable. And, as a result the loading characteristics of the strength and the maximum load also don't follow the same pattern and/or proportionality as it is displayed here below on figure 2 .

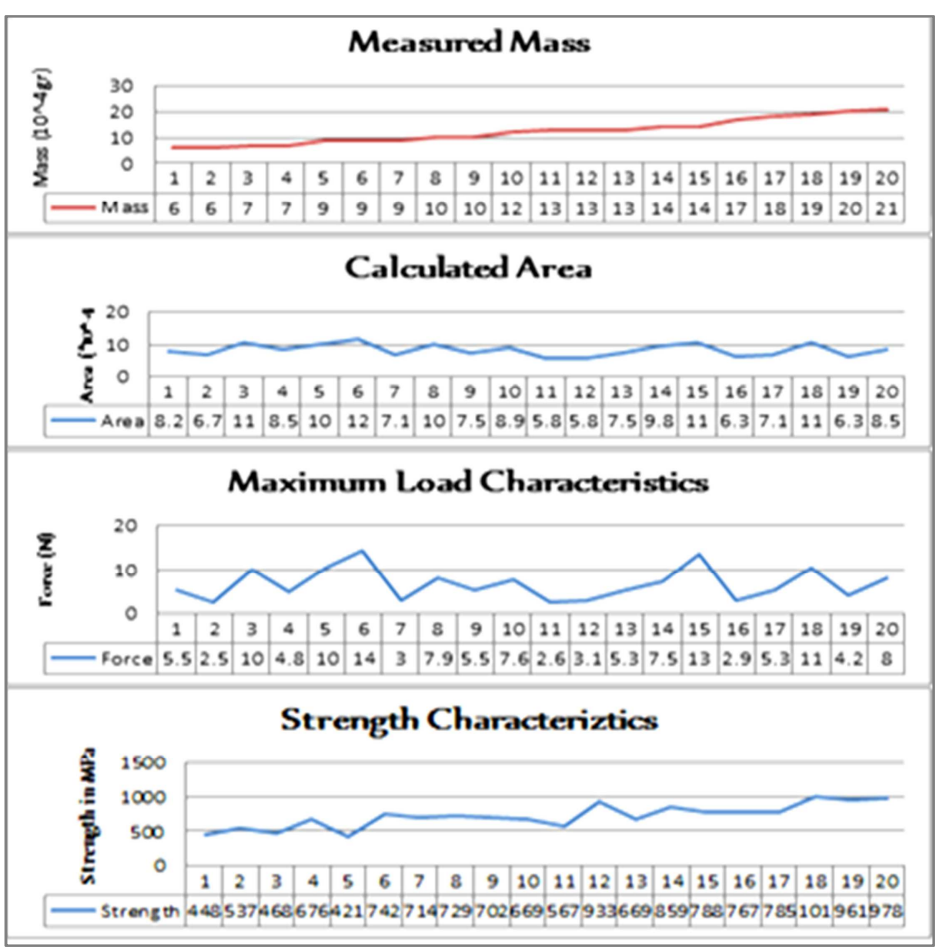

Figure 4. Hole inside a fiber and its influence. 
This inconsistency is a result of the hole inside the fiber, which is expected in the case of natural fiber. For one thing the fiber consists of hole inside and these inside holes are not uniform across the length of the fiber. Since this is the fact, the cross sectional area found by calculation is a little higher than the actual area (Since the diameter must be external diameter- internal diameter). This in general resulted in non-uniformity of pattern in shown on the above figure.

By the same token of interpreting the diameter and the cross-sectional area from mass and density relationship, the impact of the pre-load is found to be minimal as it is depicted from the regression plot generated using JMP 13 pro software package. Of course, special care has been taken to prohibit the preload no to exceed the acceptable limit which is $0.05 \mathrm{~N}$.

Generally, the analysis gave additional insight in to the contribution of the Enset fiber to enhance the strength of the resin matrix based on the direct determination of the single fiber properties. The previous research emphasized on the composite based on contribution of the fiber both at short and long fiber [3]. The result indicated that this fiber is strong and can be used for different application like the automotive and other none load bearing constructional application. Due to the hydrophilic nature of the fiber, the fiber may perform relatively less compared to other petrochemicals, even though it can be mitigated using different technics of coating. The result for flux fiber, one of the natural fibers in use for different application, showed that the young's modulus is 31 $\mathrm{GPa}$ and the strength is $305 \pm 120 \mathrm{MPa}$ for $75 \mathrm{~mm}$ Gauge 75 $\mathrm{mm}$ and $1 \mathrm{~mm} / \mathrm{min}$, green flax test [17]. Similarly, bamboo fiber was tested and found to have 33.37 Mpa young's modulus and strength of 639 for different gauges of 5, 15, 25, 35 , and $1 \mathrm{~mm} / \mathrm{min}$, steam explosion [18]. Yield of 43Mpa young's modulus and $775 \mathrm{Mpa}$ of strength has been test for different gauges of $5,10,25,40$, with $1 \mathrm{~mm} / \mathrm{min}$, mechanical extraction [19]. Thus, the result is comparable to other natural fibers that Enset fiber can be considered as one of the potential natural fiber for different nonstructural light weight application.

\section{Conclusion}

This paper characterized successfully the mechanical properties of Enset fiber which is a suitable candidate material for natural fiber reinforced composites. The characteristics were determined on a single fiber and a bundle of fiber in a composite structure.

In characterizing the properties of a single fiber, the paper dealt with the diameter variation of the fiber across the length inherently to natural fibers and the extraction method used. The variation on the diameter is the main reason for lowest limits of the strength to be very small compared to the upper limit. The use of designing the experiment, to minimize the aforementioned impact, using optimal experimental design has made the number of the experiment to be known which has significant impact on the outcome in terms of its representativeness. Hence, it would be possible to maximize these values using other ways of extraction. Measurements on fiber bundles confirm the results.

The experiments revealed adequate strength of the fiber in line with other fibers already used to reinforce composites. The moisture susceptibility of the fiber in a composite matrix could be mitigated using treatments and surface developments including alkali treatment, Silane treatment, and the combined effect of alkali and Silane treatments.

The result of the test and the analysis indicated that Enset fiber can be used for different industrial application including automotive interior part development, airplane interior and related non-load bearing parts where light weight and a minimum strength level are a design criterion.

\section{References}

[1] Alix S, Lebrun L, Marais S, Philippe E, Bourmaud A, Baley C, et al. Pectinase treatments on technical fibres of flax: effects on water sorption and mechanical properties. Carbohyd Polym 2012.

[2] Alves et al., 2010, Eco-design of automotive components making use of natural jute fiber composites, Sciences direct, 2010 .

[3] Amor IB, Rekik H, Kaddami H, Raihane M, Arous M, Kallel A Effect of Palm tree fiber orientation on electrical properties of palm tree fiber-reinforced polyester composites. J Compos Mater 2010; 44 (13): 1553-68.

[4] Aseer et al., 2013, Morphological, Physical, and Thermal Properties of Chemically Treated Banana Fiber, Journal of natural fiber, 2013.

[5] ASTM C1557-14. Standard test method for tensile strength and young's modulus of fibers. In: ASTM international, West Conshohocken, PA., www. astm.org.

[6] Baghaei B, Skrifvars M, Salehi M, Bashir T, Rissanen M, Nousiainen P. Novel aligned hemp fibre reinforcement for structural biocomposites: porosity, water absorption, mechanical performances and viscoelastic behaviour. Composites Part A 2014; 61: 1-12.

[7] Brahim SB, Cheikh RB. Influence of fibre orientation and volume fraction on the tensile properties of unidirectional Alfa-polyester composite. Compos SciTechnol 2007; 67 (1): $140-7$.

[8] Č. Mizera1, et al., 2015, Mechanical behavior of polymeric composite with fibres of false banana (Ensete ventricosum), Agronomy Research, 2015.

[9] Defoirdt N, Biswas S, De Vriese L, Tran LQN, Van Acker J, Ahsan Q, et al. Assessment of the tensile properties of coir, bamboo and jute fibre. Compos Part A-Appl Sci Manuf 2010.

[10] Delphine Depuydt et al., 2017, Digital image correlation as a strain measurement technique for fibre tensile tests, Elseveir, 2017.

[11] Dunne, R. Desai, D., Sadiku, R., Jayaramudu, J, 2016, A review of natural fibres, their sustainability and automotive applications Journal of Reinforced Plastics and Composites, 2016. 
[12] Haag K, Mussig J. Scatter in tensile properties of flax fiber bundles: influence of determination and calculation of the cross-sectional area. J Mater Sci 2016.

[13] Herrera-Franco PJ, Valadez-Gonzalez A. A study of the mechanical properties of short natural-fiber reinforced composites. Composites Part B 2005; 36 (8): 597-608.

[14] Katharina Albrecht et.al, 2018, Length Reduction in Natural Fibre-Reinforced Polymers during Compounding and Injection Moulding-Experiments Versus Numerical Prediction of Fibre Breakage, Journal of Composites Science, 2018

[15] Kim JH, Heckert NA, Mates SP, Seppala JE, McDonough WG, Davis CS, et al. Effect of fiber gripping method on the single fiber tensile test: II. Comparison of fiber gripping materials and loading rates. J Mater Sci 2015.

[16] Lu et al., 2003, Study of the properties of biocomposites. Part I Cassava starch-green coir fibers from Brazil, Elsevier, 2003.

[17] Mominul Haque et al., 2009, Physicomechanical Properties of Chemically Treated Palm Fiber Reinforced Polypropylene Composites, Journal of Reinforced Plastics and Composites, 2009.

[18] Norman DA, Robertson RE. The effect of fiber orientation on the toughening of short fiber-reinforced polymers. J Appl Polym Sci 2003; 90 (10): 2740-51.
[19] Omar Faruk Mohini Sain, Bio-fiber Reinforcements in Composite Materials, first edition, Elsevier, 2014.

[20] Osorio L, Trujillo E, Van Vuure AW, Verpoest I. Morphological aspects and mechanical properties of single bamboo fibers and flexural characterization of bamboo/epoxy composites. J Reinf Plast Compos 2011.

[21] Shah DU, Nag RK, Clifford MJ. Why do we observe significant differences between measured and 'back-calculated' properties of natural fibers? Cellulose 2016.

[22] Sharifah \& Martin, 2004, Review: finite element analysis of stress transfer in short-fibre composite materials, Composites Science and Technology, 2004.

[23] Soo-Jin Park, Min-Kang Seo, 2011, Research and Markets; Interface Science and Composites. Interface Science and Technology Part No. 18, Elsevier Science and Technology's new report, 2011.

[24] Thomason JL, Carruthers J, Kelly J, Johnson G. Fiber cross-section determination and variability in sisal and flax and its effects on fiber performance characterisation. Compos Sci Technol 2011. 